\section{类産素对破伤風毒素的 書性的改变作用}

破伤風类毒素脱毒武驗历来所采用的方法，都对 实驗动物的种类和大小、注入途徑、部位和注入量以 及覌祭方法作了明确的規定，以氺取得一致的測定結 果。作者根据斥日的經驗, 認为类毒素脫毒的难易, 不仅因測定方法、类毒素含氮量、福尔馬林加入量和 培育情况有所不同，而且和类毒素的質量之間似乎也 有关系。以下所述只限于类毒素本身对破伤風毒素青 性改变的覌察。

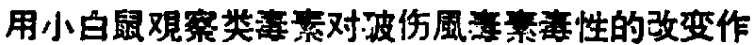
用

取小白鼣(16-20 克)108 只, 分为三組，其中一 組为对照組。試驗組分別用一批質量好的类毒素 (214 号) 及一批質量美的类䓯素 (205 号) 按不同剂量 注: 入皮下（2 毫升剂量注入背部皮下， 1 毫升及 0.5 毫升 注入大腿皮下)。所用类毒素均于事先加入一定量 的毒素 (中检 6 号标准毒素), 使每毫升类毒溸会 0.6 m.1.d. 毒素。对照毒素用肉湯稀釋而成，每毫升 亦会 $0.6 \mathrm{~m} .1 . \mathrm{d}$. 毒素。注射后覌察 10 日，結果見表 1 。

由表 1 可知，类垡素不仅能改变毒素对小白鼠的 毒性作用, 使症状减輕, 死亡时間超楥和死亡数减少, 且当使用高价类毒素 (214 号类毒素結合力为 $90 \mathrm{Ec} /$ $\mathrm{ml}$ ) 稀釋瑇素时，注入 $0.6 \mathrm{~m} . \mathrm{l} . \mathrm{d}$. 毒素也不致使动物 酸拝或死亡。低价类毒素 (205 号类毒素結合力为 35 $\mathrm{Ec} / \mathrm{ml}$ ) 則不然, 注入 $1.2 \mathrm{~m} . \mathrm{l} . \mathrm{d}$. 毒素, 症状出現較 早, 死亡时間加速, 在注射后第 8 日全部死亡; 注入 0.6 m.1.d. 毒素, 有产症及部分死亡; 注入 0.3 m.1.d. 毒素, 不破症也不死亡, 与对照显然不同。

表 1

\begin{tabular}{|c|c|c|c|c|c|c|c|c|}
\hline \multirow{2}{*}{ 类毒素号 } & \multirow{2}{*}{$\begin{array}{l}\text { 注入量 } \\
\text { (毫升) }\end{array}$} & \multicolumn{4}{|c|}{ 結 } & \multicolumn{3}{|c|}{ 果 } \\
\hline & & 4 日! & 5 日 & 6 日 & 7 日 & 8 日 & $\begin{array}{ll}9 & \text { 日 }\end{array}$ & 10 日 \\
\hline \multirow{3}{*}{214} & 2 & & & $\underline{|\bar{t}|}$ & $\overline{\mathbf{T}}$ & $1 / 12$ & $3 / 12$ & $3 / 12$ \\
\hline & 1 & & & - & - & - & - & - \\
\hline & 0,5 & & & - & - & - & - & - \\
\hline \multirow{3}{*}{205} & 2 & & $|\mathbf{t}|$ & $2 / 12$ & $10 / 12$ & $12 / 12$ & & \\
\hline & 1 & & & $|\mathbf{t}|$ & $\underline{|t|}$ & & $1 / 12$ & $1 / 12$ \\
\hline & 0,5 & & & - & - & - & - & - \\
\hline \multirow{3}{*}{ 对 照 } & 2 & $12 / 12$ & & & & & & \\
\hline & 1 & $\mathbf{t}$ & $5 / 12$ & & $11 / 1$ & $12 / 12$ & & \\
\hline & 0,5 & $t$ & & & $\mathrm{~T}$ & & & $T$ \\
\hline
\end{tabular}

注: 经类毒素抗原性試驗証明, 214 号的筫量 优于 205 \%. 口二全身庭状，病鼠不能翻身; $\mathrm{t}, \mathrm{T}=$ 局部应状严重程度; -二末酸应; 分母=使用小白鼠数; 分子=死亡小白鼠数。
表 2

\begin{tabular}{|c|c|c|c|c|c|c|c|c|c|c|c|}
\hline \multirow{2}{*}{ 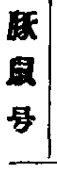 } & \multirow{2}{*}{$\begin{array}{l}\text { 类 } \\
\text { 眚 } \\
\text { 素 } \\
\text { 奇 }\end{array}$} & \multicolumn{2}{|c|}{$\begin{array}{l}\text { 注入量 } \\
\text { (就) }\end{array}$} & \multicolumn{5}{|c|}{ 絬 } & \multicolumn{3}{|c|}{ 果 } \\
\hline & & \multicolumn{2}{|c|}{ 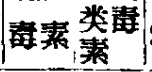 } & 2 日 & 3 日 & 4 日 & {$\left[\begin{array}{ll}5 & \text { 日 }\end{array}\right.$} & 7 日 & 10 日 & 15 日 & 21 日: \\
\hline 1 & & 2 & 8 & - & & & 死 & & & & \\
\hline 2 & & 2 & 8 & - & & & & 死 & & & \\
\hline 3 & & 2 & 3 & t & & 死 & & & & & \\
\hline 4 & & 2 & 3 & T & & & 死 & & & & \\
\hline 5 & & 1 & 9 & - & & & (T) & & & $t$ & - \\
\hline 6 & & 1 & 9 & - & & & [1] & & & (T) & - \\
\hline 7 & 212 & 1 & 4 & - & & & (T) & 死 & & & \\
\hline 8 & - & 1 & 4 & - & & & [T] & 死 & & & \\
\hline 9 & & 1 & 1 & $\mathbf{t}$ & & & 死 & & & & \\
\hline 10 & 210 & 1 & 1 & $t$ & & & 死 & & & & \\
\hline 11 & & 0.5 & 9.5 & $\longrightarrow$ & & & & $\mathrm{T}$ & [T] & {$[\mathbf{t}]$} & - \\
\hline 12 & & 0.5 & 9.5 & 一 & & & & t] & [T] & - & - \\
\hline 13 & & 0.5 & 4.5 & - & & & [T] & (T) & [1] & - & - \\
\hline 14 & & 0.5 & 4.5 & - & & & $t$ & [T] & T] & - & - \\
\hline 15 & & 0.5 & 1.5 & - & & & {$[\overline{\mathbf{t}}]$} & {$[\Gamma]$} & {$[\mathrm{T}]$} & - & - \\
\hline 16 & & 0.5 & 1.5 & $\rightarrow$ & & & $t$ & [1] & [1] & - & - \\
\hline 17 & & 2 & 8 & t & & 死 & & & & & \\
\hline 18 & & 2 & 8 & - & & 死 & & & & & \\
\hline 19 & & 2 & 3 & $\mathbf{t}$ & & 死 & & & & & \\
\hline 20 & & 2 & 3 & $\mathbf{t}$ & 死 & & & & & & \\
\hline 21 & & 1 & 9 & - & & & 死 & & & & \\
\hline 22 & & 1 & 9 & $t$ & & & 死 & & & & \\
\hline 23 & & 1 & 4 & $\mathbf{t}$ & & & 死 & & & & \\
\hline 24 & 178 & 1 & 4 & t & & & [1] & 死 & & & \\
\hline 25 & 110 & 1 & 1 & $\mathrm{t}$ & & & 死 & & & & \\
\hline 26 & & 1 & 1 & $\mathbf{t}$ & & & 死 & & & & \\
\hline 27 & & 0.5 & 9.5 & 一 & & & {$[T]$} & [T] & [T] & - & - \\
\hline 28 & & 0.5 & 9.5 & - & & & [T] & [T] & [T] & - & - \\
\hline 29 & & 0.5 & 4.5 & 一 & & & [1] & {$[\Gamma]$} & [T] & - & - \\
\hline 30 & & 0.5 & 4.5 & - & & & {$[t$} & {$[\mathrm{T}]$} & [T] & - & - \\
\hline 31 & & 0.5 & 1.5 & $\mathbf{t}$ & & & [T] & [T] & [T] & {$[t]$} & - \\
\hline 32 & & 0.5 & 1.5 & $t$ & & & $t$ & [1] & [T] & - & - \\
\hline 33 & & 2 & 8 & $T$ & 死 & & & & & & \\
\hline 34 & & 2 & 8 & T] & 死 & & & & & & \\
\hline 35 & & 2 & 3 & $\mathrm{~T}$ & 死 & & & & & & \\
\hline 36 & & 2 & 3 & $\mathrm{~T}$ & 死 & & & & & & \\
\hline 37 & & 1 & 9 & $t$ & & 死 & & & & & \\
\hline 38 & & 1 & 9 & $t$ & & & 死 & & & & \\
\hline 39 & 개쓸 & 1 & 4 & $\mathbf{t}$ & & & 死 & & & & \\
\hline 40 & 类毒 & 1 & 4 & $\mathrm{~T}$ & & & 死 & & & & \\
\hline 41 & 萎 & 1 & 1 & $\mathbf{t}$ & & & 死 & & & & \\
\hline 42 & (178) & 1 & 1 & $\mathrm{~T}$ & & & 死 & & & & \\
\hline 43 & & 0.5 & 9.5 & - & & & [T] & 死* & & & \\
\hline 44 & & 0.5 & 9.5 & - & & & [1] & [T & T & $t$ & - \\
\hline 45 & & 0.5 & 4.5 & $\mathbf{t}$ & & & [T] & $T$ & 死 & & \\
\hline 46 & & 0.5 & 4.5 & $t$ & & & [T] & {$[\mathrm{T}]$} & [T] & - & 一 \\
\hline 47 & & 0.5 & 1.5 & $t$ & & & [T] & $T$ & 死 & & \\
\hline 48 & & 0.5 & 1.5 & $t$ & & & [1] & [T] & II & $\cdots$ & - \\
\hline 49 & & 2 & 内沙 8 & $\mathbf{t}$ & 死 & & & & & & \\
\hline 50 & & 2 & 肉湖8 & $t$ & 死 & & & & & & \\
\hline 51 & 对昭 & 2 & 内 & $\mathrm{T}$ & 死 & & & & & & \\
\hline 52 & & 2 & 内楛3 & $\mathrm{T}$ & 死 & & & & & & \\
\hline 53 &. & 2 & 0 & $\mathrm{~T}$ & 死 & & & & & & \\
\hline 54 & & 2 & 0 & $\mathbf{T}$ & 死 & & & & & & \\
\hline
\end{tabular}

- 第 6 日死亡。 
用政鼠覌察类毒素对破伤風毒素每性的改变作用

取豚鼠（300-360 克）54只, 其中 6 只作对照 用，余数分为三組。第一組用一批質量好的类毒素 《212-215 号) 作人工脫毒試驗, 第二組用一批 質量 差的类毒素 (178 号) 如法进行試驗, 第三組用募 沸 类璱素（178 号煮沸 30 分鐘）代替类毒素以資比較。 对照組以闪湯稀䆁琵素注射。注射途徑为腹股沟皮 下, 10 毫升量分作两側注射, 5 毫升及 2 毫升量均在 一侧注射。所用瑇素 (中檢 6 号标准毒素) 当日使用 前以闪湯稀釋成每毫升含 $1 / 4000$ 毫克, 亦即每毫升毒 素桸䆁液含 $1 / 2$ m.l.d.。注射量、毒素及类毒素混合 法和試驗絬果見表 2 。

由表 2 可以看出，豚鼠的反应情况，大致与小白 的的結果相似。类琵素質量較好, 注入量較多, 則發 惊及死亡时間向后推迟, 死亡数也較少。例如, 注入 1/2 m.l.d. 毒素后，212-215 号类毒素組只有 2 毫升 注入量的豚鼠于第 2 日出現局部症状抹于第 5 日死 亡, 5 毫升注入量的豚鼠于第 7 日死亡, 10 毫升注入 量的溷瓦㥅症較晚, 及至第 21 日已完全恢复正常; 而 178 号类註素組的情形与此則稍有不同, 伤諭注入量 多少, 几乎都在第 2 日發症, 有 1 只豚鼠于第 7 日死 亡, 其余均于第 5 日死亡。加热类毒素以 1 m.l.d. 毒 素攻话結果，同于肉湯对照。

其所以有此不同結果, 显然和类毒素的質量是有 关采的。加热类毒素由于其中已不含有效抗原成分, 因而其結果与肉湯对照相同。又由对照試驗得知, 注 入量多少抹不影响其最終死亡結果, 只是大剂量因单 位容积所合毒素較少, 常有早期全身症状出現。由加 热类毒素組也可得到同样說明, 以 $1 / 4$ m.l.d. 毒素攻 击后，10 毫升注入量的豚鼠虽于第 2 日未發生任何症 状, 但其晚期結果則与 2 毫升, 5 毫升注入量極为 相 似。由此可見，注入量大，表明其中类垡素含量較多， 尤其是質量好的类毒素因所含有效成分更多, 对破伤 風毒素素性的改变作用也較显著。

作者于另一实驗中 (見前一篇簡报), 曾經证明攻 毒前 5-10 小时注入类毒素, 对实驗破伤風中毒过程 确有影响, 其結果与本文所述的小白鼠实驗有相似之 处。因此，两者机制可能相同; 至于是否已在試管內 發生这和毒性改变作用, 由于缺少体外实驗方法, 頗 难加以証明。本文除在理論上須作进一步研究外, 其 在实践上的意义, 对破伤風类毒素脫畫試驗指出了一 个新的研究方向.

陈廷祚刘仁文 （大連生物制品研究所） 1957 年 9 月 30 日

\section{关于中国徑流資源的推算}

我国是个山高水长，河流众多，徑流資源特別丰 富的国家，但关于中国涇流資源的推算和估計，解放 前从汥有人研究过, 只在解放后随着国家經济建設的 进展, 才开始了这項研究工作。

估算的步慗和方法:

1. 利用已穏整理好的我国各河流的流量資料， 特別是利用了中国科学院地理研究所与水利科学研究 院合作进行的中国水文区划工作中延长插补过的資 料。但由于各河河口海潮上溯或因其他关系，河口上 汥有流量測站，因此河流最下游的流童站資料还不能 代表整个流域的徑流量; 为了求得各河徑流入海的 徑流量, 就必須求出各河最下游流量站以下流域面积 的徑流量。求的方法是首先根据中国徑流模数等值綡 圖(在进行此項工作时該圖已完成)推估各河最下游流 量站至河口間流域范图內的单位面积的徑流模数（秒 公升/方公里)，与該段流域面积的乘积，作为該段流 域面积所产生的徑流; 然后与河流最下游流量站的 徑流数值加在一起, 即为各河河口每年徑流入海的 徑流量，（穿越国界的河流也是这样求出的。見表 $\rightarrow)$

2. 利用我国已进行了的或正在进行的各河流域規 划对各河徑流資源計算的成果, 如辽河、溜河、海 河、㣴河、淮河等。此外也利用了当地水利部門現成 的估計数字, 如新疆各地区。

3. 利用水利部門和水电部門一些新查盽和推佔的 数值，如西南地区的瀾滄江、怒江各河和藏北、河西、 青海各內陆流域，以及新疆阿尔泰地区各河。

4. 沒有覌测資料而又沒有現成的可靠的估算成果 的地区，則依据其流域面积扑参照徑流模数等值綫圖 計算, 其方法与計算河流最下游流量站至河口段流域 面积所产徑流的方法是一样的。在表二中“流域平均徑 流模数”項队加括号的河流都是这样求出的。

5. 一些国际河川，凡上游在我国们下游在邻国的 都計算到穿越国界处的徑流量, 如瀾渝江、怒江、類尔 齐斯河、伊犁河、綏芬河、雅鲁藏布江、紅河等。凡 上游在邻国而下游在我国的河流，都計算其奎部徑流 量, 如西江支流左江上源在越南境內、額尔齐斯河上 源在蒙古和苏联境內等情况, 都未减去国外流域面积 所产徑流。但沿国界而行的两国共有的河川, 則只計 算了我国領域內所产徑流，如黑龙江中上游、烏苏里 江、鴨緑江和圖們江等, 其計算方法与上 項 方 法相 同。 